\title{
In vitro metabolic labeling of intestinal microbiota for quantitative metaproteomics
}

Xu Zhang ${ }^{1}$, Zhibin Ning ${ }^{1}$, Janice Mayne ${ }^{1}$, Shelley A. Deeke ${ }^{1}$, Jennifer Li $^{1}$, Amanda E. Starr ${ }^{1}$, Rui Chen $^{1}$, Ruth Singleton ${ }^{2}$, James Butcher ${ }^{1}$, David R. Mack ${ }^{2, *}$, Alain Stintzi ${ }^{1, *}$, and Daniel Figeys ${ }^{1, *}$

${ }^{1}$ Ottawa Institute of Systems Biology and Department of Biochemistry, Microbiology and Immunology, Faculty of Medicine, University of Ottawa, Ottawa, ON, Canada, K1H 8M5;

${ }^{2}$ CHEO Inflammatory Bowel Disease Centre and Research Institute, and Department of Paediatrics, University of Ottawa, Ottawa, ON, Canada, K1H 8L1.

*Corresponding authors: Daniel Figeys, E-mail, dfigeys@uottawa.ca, Tel: 613-562-5800 ext 8674; Alain Stintzi, E-mail, astintzi@,uottawa.ca, Tel: 613-562-5800 ext 8216; David Mack, Email, dmack@cheo.on.ca, Tel: 613-737-7600 ext 4113.

\section{This supporting information contains:}

Supporting Materials and Methods

Table S1-S4

Figure S1-S6 


\section{Supporting Materials and Methods}

In vitro ${ }^{15} \mathrm{~N}$ isotopically metabolic labeling of the human intestinal microbiota

Mucosal-luminal interface (MLI) samples were collected from the distal colon of five different volunteers (three male and two female; age range: 14 to 17 years; Table S1) and were used for the in vitro metabolic labeling. MLI sample collections were performed according to the following standard protocols. Briefly, all individuals were scheduled to undergo colonoscopy as part of their clinical care. None had (1) use of any antibiotics or probiotics within the four weeks prior to colonoscopy, (2) infectious gastroenteritis within the preceding two months, or (3) inflammatory bowel disease. Colonoscopy preparation was conducted as per standard protocol reported previously, ${ }^{1}$ and the protocol was approved by the Research Ethics Board of the Children's Hospital of Eastern Ontario (CHEO). MLI samples were obtained from macroscopically normal areas of the distal colon. At the distal colon, fluid from the colonic lumen was aspirated through the colonoscope into a sterile container, the mucosa was flushed with sterile water and the mixture of water and intestinal content was again aspirated into the sterile container through a colonoscope. Samples were immediately placed on ice in the endoscopy suite and transported to an anaerobic workstation $\left(37^{\circ} \mathrm{C}, 10 \% \mathrm{H}_{2}, 10 \% \mathrm{CO}_{2}\right.$, and $80 \%$ $\mathrm{N}_{2}$; Don Whitley Scientific Ltd, UK).

In the anaerobic workstation, large particles were removed by filtering through sterilized gauze, and the flow through was inoculated at a ratio of $2 \% \mathrm{w} / \mathrm{v}(\sim 0.02 \mathrm{~g}$ fecal slurry mass per $\mathrm{mL}$ medium) into $5 \mathrm{~mL}$ modified ${ }^{15} \mathrm{~N}$-labelled bacteria growth medium. The basic ${ }^{15} \mathrm{~N}$ bacteria growth medium was purchased from Cambridge Isotope Laboratories, Inc, MA (Item \# CGM$1000-\mathrm{N} ; \mathrm{U}-15 \mathrm{~N}, 98 \%$ ). As described in the manufacture's instruction, the medium was prepared 
from the hydrolysates of ${ }^{15} \mathrm{~N}$ fully labelled algae and comprised of a complex mixture of glucose, amino acids, minerals, cofactors, etc. The medium had been previously filtered through a 0.22 $\mu \mathrm{m}$ sterile filter (Pall Corporation, NY), pre-reduced with $0.1 \% \mathrm{w} / \mathrm{v}$ sodium thioglycolate, ${ }^{2}$ and supplemented with $0.5 \mathrm{~g} / \mathrm{L}$ bile salts (Sigma-Aldrich Co.) which are important substrates of many intestinal bacteria. ${ }^{3}$ The in vitro cultures were passaged every 24 hours into fresh medium with an inoculum rate of $10 \% \mathrm{v} / \mathrm{v}$, and samples were collected at each day/passage for immediate sample processing as described below.

Microbial cell harvesting, protein extraction, in-solution trypsin digestion, and mass spectrometry analysis

Microbial cells were harvested from the culture samples by differential centrifugation as previously described. ${ }^{4}$ Briefly, each culture was first centrifuged at $300 \mathrm{~g}$ for $5 \mathrm{~min}$ at $4{ }^{\circ} \mathrm{C}$. Supernatants were carefully collected into a new tube and subjected to two additional centrifugations at $300 \mathrm{~g}$ for $5 \mathrm{~min}$ at $4^{\circ} \mathrm{C}$ to remove debris. The collected supernatant was then centrifuged at $14,000 \mathrm{~g}$ for $20 \mathrm{~min}$ at $4^{\circ} \mathrm{C}$ to pellet microbial cells. Pellets were re-suspended in ice-cold PBS and centrifuged at $14,000 \mathrm{~g}$ for $20 \mathrm{~min}$ at $4{ }^{\circ} \mathrm{C}$ to pellet microbial cells. The washing was repeated for two additional times. The resulting microbial cell pellets were stored at $-80^{\circ} \mathrm{C}$ or immediately used for protein extraction.

To extract proteins, microbial cells were re-suspended in $200 \mu \mathrm{L}$ lysis buffer $(4 \% \mathrm{w} / \mathrm{v}$ sodium dodecyl sulfate (SDS) and $8 \mathrm{M}$ urea in $50 \mathrm{mM}$ Tris $\mathrm{HCl}$; $\mathrm{pH} 8.0$ ) and lysed with sonication (three cycles of 20s sonication with 60s interval on ice; amplitude, 25\%; Qsonica, CT). Cell debris was then removed by centrifugation at $16,000 \mathrm{~g}$ for $10 \mathrm{~min}$ at $4^{\circ} \mathrm{C}$. Proteins were precipitated from 
the supernatant by using 10 volumes of acidified acetone/ethanol buffer (acetone: ethanol: acetic acid $=50: 50: 0.1 \mathrm{v} / \mathrm{v} / \mathrm{v}$ ) at $-20^{\circ} \mathrm{C}$ overnight and were pelleted by centrifugation at $16,000 \mathrm{~g}$ for 25 min at $4{ }^{\circ} \mathrm{C}$. Three ice-cold acetone washes were used to remove residual SDS, ${ }^{5}$ and the resulting protein pellets were then re-suspended in $8 \mathrm{M}$ Urea, $50 \mathrm{mM}$ ammonium bicarbonate $(\mathrm{pH} 8.0)$ for in-solution trypsin digestion and mass spectrometry (MS) analysis.

The concentration of protein lysate was determined using the DC protein assay (Bio-Rad Laboratories, Inc), and $100 \mu \mathrm{g}$ of protein lysate was subjected to in-solution trypsin digestion as previously described. ${ }^{6}$ Briefly, proteins were first reduced with $10 \mathrm{mM}$ dithiothreitol (DTT) then alkylated with $20 \mathrm{mM}$ iodoacetamide (IAA). The urea concentration was then diluted to $<1 \mathrm{M}$ with $50 \mathrm{mM}$ ammonium bicarbonate. Trypsin (Worthington Biochemical Corp., Lakewood, NJ) was then added at a protein-trypsin ratio of 50:1 w/w for overnight digestion with gentle agitation at $37^{\circ} \mathrm{C}$. Tryptic digests were then desalted with a $10 \mu \mathrm{m} \mathrm{C} 18$ column and eluted with $200 \mu \mathrm{L} 80 \% \mathrm{v} / \mathrm{v}$ acetonitrile/0.1\% v/v formic acid. Eluents were dried with a Speed-Vac concentrator (ThermoFisher Scientific, Inc), and tryptic peptides were dissolved in $100 \mu \mathrm{L} 0.1 \%$ v/v formic acid for MS analysis.

Tryptic peptides equivalent to $4 \mu \mathrm{g}$ of proteins were loaded for LC-MSMS analysis on a LTQ Velos Pro Orbitrap Elite mass spectrometer (ThermoFisher Scientific, Inc). Peptide separation was performed on an analytical column $(75 \mu \mathrm{m} \times 10 \mathrm{~cm})$ packed with reverse phase beads. A two or four hour gradient was performed from $5-35 \% \mathrm{v} / \mathrm{v}$ acetonitrile containing $0.1 \% \mathrm{v} / \mathrm{v}$ formic acid at a flow rate of $200 \mathrm{~nL} / \mathrm{min}$. The instrument method consisted of one full MS scan from 350 to $1750 \mathrm{~m} / \mathrm{z}$ followed by a data-dependent MS/MS scan of the 20 most intense ions, a dynamic exclusion repeat count of 2 , and a repeat exclusion duration of $30 \mathrm{~s}$. All data were recorded with the Xcalibur software and exported as a RAW format. 
Mass spectrometry data processing and analysis

For peptide identification, each raw file was converted into mgf format using an in-house software suite (Proteomics Tool Suite, v3.9.3). The database search was performed using $\mathrm{X}$ !tandem (http://www.thegpm.org) ${ }^{7}$ against an customized Human Intestinal Microbial Protein Database (HIMPD). The HIMPD database was established based on Human Microbiome Project $(\text { HMP })^{8}$ reference genome catalog (gastrointerstinal_tract, downloaded on July, 2014) by adding known intestinal microbes including Archaea and Fungi species, which eventually consists of 2,044,279 protein sequences from 465 microbial species/strains (Table S4). A two-step database search strategy was performed for peptide/protein identification as previously described. ${ }^{9}$ Briefly, all spectra were first searched against a "target-only" version of HIMPD database; all matched protein sequences were extracted to generate a reduced database. A "target-decoy" database was then created with the reduced version of database and was used for a second step database search. A precursor mass tolerance of $10 \mathrm{ppm}$ and $0.6 \mathrm{Da}$ for fragment ions was used, and a maximum of 2 missed trypsin cleavages was allowed. Cysteine carbamidomethylation was set as a fixed modification; methionine oxidation and protein N-terminal acetylation were set as variable modifications. Database search results were then parsed using the Proteomics Tool Suite with a peptide-level false discovery rate (FDR) cut-off of 0.01 . Proteins which could be identified by the same set or subset of peptides were grouped together as one protein group.

The taxonomic classification of the peptide sequences was performed in Unipept (v3.0, http:// unipept.ugent.be). ${ }^{10,11}$ For taxonomic comparisons between the initial inoculum (Passage 0) and the SILAMi reference, all identified ${ }^{14} \mathrm{~N}$ unique peptides in Passage 0 and ${ }^{15} \mathrm{~N}$ unique peptides in 
SILAMi were analysed. Taxa were considered present if they had $\geq 2$ detected unique peptide sequences. Taxonomic trees were generated in PhyloT (http://phylot.biobyte.de/).

The ${ }^{15} \mathrm{~N}$ enrichment rate for each identified peptide was calculated using a Census software based on the algorithm reported by MacCoss et al. ${ }^{12}$ Briefly, the peptide isotope distribution over a range of enrichments was predicted for each identified peptide. Subsequently, the experimental isotope distribution was compared to the predicted distributions. The enrichment of the predicted isotopic distribution, which had the best match with experimental isotopic distribution, was considered as the ${ }^{15} \mathrm{~N}$ enrichment rate for the identified peptide. Average enrichment rate of all identified peptides in a sample was used as the ${ }^{15} \mathrm{~N}$ enrichment rate of sample.

Light-to-heavy $(\mathrm{L} / \mathrm{H})$ ratios of the identified peptides and protein groups for the spike-in samples were also calculated with Census as previously described. ${ }^{13,14}$ Briefly, ${ }^{14} \mathrm{~N}$ and ${ }^{15} \mathrm{~N}$ peptides were first identified by searching against the HIMPD database. DTAselect format identification results and ms 1 files were generated using Proteomics Tool Suite and subjected for quantitation analysis in Census (http://fields.scripps.edu/census/). Census calculates the $\mathrm{L} / \mathrm{H}$ ratio for each identified peptide using a linear least-squares correlation approach. ${ }^{13}$ Protein ratios were then estimated by averaging all peptide ratios within a specific protein group. Default parameters in Census (a determination factor of 0.5 and an outlier $p$ value of 0.1 ) were used to filter out poor-quality peptide quantifications. Singleton peptides/proteins, which were also detected in Census, ${ }^{13}$ were not used in this study.

DNA extraction, bacterial $16 S$ rDNA V6 region sequencing, and data analysis 
DNA extraction for 16S rDNA V6 sequencing was performed using a Fast DNA spin kit (MP Biomedicals, Santa Ana, CA) and a FastPrep-24 (MP Biomedicals) as previously described. ${ }^{15}$ Briefly, microbial pellets harvested before and after SILAMi labeling were re-suspended in $1 \mathrm{~mL}$ of Cell Lysing Solution (CLS)-TC followed by two cycles of mechanical lysis at speed 6.0 for 40 seconds. SPIN kit columns were washed, and the extracted DNA was eluted in DNase-free water. 50 ng of genomic DNA was then used to for library construction, which consisted of two successive PCR rounds with primers that targeted the V6 region of the 16S rRNA gene and added barcodes, and subsequently incorporate Illumina sequencing adapters. Final PCR products were purified and equimolar combinations of each sample reaction were combined for sequencing.

Paired-end sequencing (100 bp read length) was performed on an Illumina HiSeq 2000 at the Center for Applied Genomics (Toronto, Canada). The raw reads were processed as described previously with minor modifications. ${ }^{15}$ Briefly, the paired-end reads were merged using FLASh, ${ }^{16}$ quality filtered with FastX-toolkit (http://hannonlab.cshl.edu/), demultiplexed using FastQMultX, ${ }^{17}$ and reformatted using PRINSEQ.${ }^{18}$ Operational Taxonomic Unit (OTU) picking were performed in QIIME (version 1.8.0) ${ }^{19}$ at the $97 \%$ level using a closed reference OTU picking strategy against the Greengenes database (version 13.5) using the UCLUST algrithum. ${ }^{20,21}$ The resulting OTU table was used to calculate the presence/absence of taxa at various taxonomic levels in the initial inoculum (Passage 0) and the SILAMi reference. Taxa were considered present if their relative abundance was $\geq 0.0001 \%$. Taxonomic trees were visualized using the phyloseq R package. ${ }^{22}$ 
In vitro modulating effects of fructo-oligosaccharide (FOS) on microbiota

A fresh MLI sample from one volunteer (individual 5) was inoculated into basal culture medium (BCM; $2 \mathrm{~g} / \mathrm{L}$ peptone water, $2 \mathrm{~g} / \mathrm{L}$ yeast extract, $0.1 \mathrm{~g} / \mathrm{L} \mathrm{NaCl}, 40 \mathrm{mg} / \mathrm{L} \mathrm{K}_{2} \mathrm{HPO}_{4}, 40 \mathrm{mg} / \mathrm{L}$ $\mathrm{KH}_{2} \mathrm{PO}_{4}, 10 \mathrm{mg} / \mathrm{L} \mathrm{MgSO}{ }_{4} \cdot 7 \mathrm{H}_{2} \mathrm{O}, 10 \mathrm{mg} / \mathrm{L} \mathrm{CaCl} \cdot 6 \mathrm{H}_{2} \mathrm{O}, 2 \mathrm{~g} / \mathrm{L} \mathrm{NaHCO} 3,0.05 \%$ L-Cysteine, 0.5 $\mathrm{g} / \mathrm{L}$ bile salts, $10 \mu \mathrm{l} / \mathrm{L}$ Vitamin $\mathrm{K}, 2 \mathrm{ml} / \mathrm{L}$ Tween 80 and $5 \mathrm{mg} / \mathrm{L}$ hemin $)^{23,24}$ at an inoculum ratio of $2 \% \mathrm{w} / \mathrm{v}(\sim 0.02 \mathrm{~g}$ fecal slurry mass $/ \mathrm{ml}$ medium), and co-cultured with or without $10 \mathrm{mg} / \mathrm{ml}$ FOS (product no. F8052, Sigma) in an anaerobic workstation $\left(37^{\circ} \mathrm{C}, 10 \% \mathrm{H}_{2}, 10 \% \mathrm{CO}_{2}\right.$, and $80 \% \mathrm{~N}_{2}$ ). Three replicates were conducted for each group, and samples were collected at 0,13 and 36 hours, respectively. Bacterial cells were harvested and proteins were extracted as described above. The SILAMi proteins were then spiked into each of the unlabelled samples at a 1:1 ratio followed by in-solution trypsin digestion, desalting and HPLC-MS/MS analysis as described above. Principal component analysis (PCA) and score plotting were performed with Matlab (The MathWorks, Inc., USA). Missing values were imputed using a nearest-neighbor method in Matlab with knnimpute function.

Different proteins with statistical significance between samples with and without FOS treatments at $36 \mathrm{hr}$ were identified using a two-sample t-test followed by Benjamin-Hochberg FDR correction. Identified proteins with FDR-corrected $p<0.05$ and $>2$ fold changes were used for pathway analysis in iPATH v2 (http://pathways.embl.de/iPath2.cgi). ${ }^{25}$ To generate an iPATHcompatible data type, all key proteins were subjected to BLASTP against a cluster of orthologous group (COG) database (downloaded from NCBI, ftp://ftp.ncbi.nih.gov/pub/COG/COG) with an E-value cut-off of 0.01 and bit-score cut-off of $30 .{ }^{26}$ The best hit for each query was selected for annotation with the COG ID, name and category information for each of the matched sequences were extracted from the annotation file 
of the COG database. If the leading protein (defined as the top ranking protein within a protein group, where ranking is based on the number of peptide sequences, the number of PSMs, and the sequence coverage) had no COG ID match, other proteins within that protein group were checked for potential matches. The COG IDs were then used for pathway analysis in iPATH v2.

\section{In vitro modulations of monosaccharides on the human intestinal microbiota}

Five different monosaccharides, namely L-(-)-Fucose, D-(+)-Mannose, D-(+)-Glucose, D-(+)Galactose, and N-acetyl-D-glucosamine (GlcNAc), were purchased from Sigma (Sigma-Aldrich Co.) and used for in vitro co-culturing with intestinal microbiota under anaerobic conditions. Briefly, a fresh MLI sample was collected as described above and inoculated (at an inoculum ratio of $2 \% \mathrm{w} / \mathrm{v}$ ) into $\mathrm{BCM}$ media $^{23,24}$ with or without $2.5 \mathrm{~g} / \mathrm{L}$ of one of the five different monosaccharides. After 18 hours of co-culturing, samples were collected for SILAMi-based metaproteomic analysis. A total of 18 culture samples (three replicates for each of the five monosaccharides and a non-treated control condition) were obtained.

Sample processing, protein/peptide identification, and protein/peptide quantification were performed as described above. All calculated $\mathrm{L} / \mathrm{H}$ ratios of protein groups for the 18 samples were combined and imported into Perseus (version 1.5.2.4) for filtering and statistical analysis. Only protein groups with valid $\mathrm{L} / \mathrm{H}$ ratio values in at least half of the samples ( 9 of 18 samples) were used. Pairwise comparisons between each monosaccharide group and the non-treated control were performed using a two-sample t-test. Benjamin-Hochberg FDR was applied to evaluate significance, where proteins with $>2$ fold differences and an FDR-corrected $p$ value $<$ 
0.05 were considered as significant proteins. $\log _{2}$-transformed ratios were used for hierarchical clustering in Perseus based on Euclidean distance.

\section{Supporting Tables}

Table S1 Characterizations of individuals involved in mucosal-luminal interface (MLI) aspirate sample collections

\begin{tabular}{ccccc}
\hline Subject & Gender & Age (years) & $\begin{array}{c}\text { Body weight } \\
\text { (kg) }\end{array}$ & $\begin{array}{c}\text { Height } \\
\text { (cm) }\end{array}$ \\
\hline Individual 1 & Male & 14 & 63.3 & 157.3 \\
Individual 2 & Male & 15 & 44.5 & 153.1 \\
Individual 3 & Male & 17 & 96 & 194.5 \\
Individual 4 & Female & 16 & 29.6 & 138.4 \\
Individual 5 & Female & 16 & 90.2 & 161.9 \\
\hline
\end{tabular}

Table S2 List of 187 proteins altered by fructo-oligosaccharide

(See file Table S2.xls)

Table S3 List of 246 key proteins modulated by the supplement of different monosaccharides (See file Table S3.xls)

Table S4 List of 465 microbial species/strains included in the human intestinal microbial protein database

(See file Table S4.xls) 


\section{Supporting Figure Legends}

Figure S1 ${ }^{14} \mathrm{~N}$ and ${ }^{15} \mathrm{~N}$ peptide identification for each passage of the five human MLI microbiota during metabolically labeling. The mean and standard error of the identified unique peptide sequences are shown.

Figure S2 MLI microbiota composition at the initial inoculum (Passage 0) and SILAMi at phylum and genus levels. Taxonomic analysis was performed using both 16S rDNA V6 region sequencing and metaproteomics. For metaproteomic analysis, phyla (A) and genera (B) were considered present if they had $\geq 2$ detected unique peptide sequences. For $16 \mathrm{~S}$ rDNA analysis, phyla (C) and genera (D) were considered present if they had a relative abundance $\geq 0.00001 \%$. Orange indicates the presence of the taxa in only Passage 0 , while purple indicates the taxa are present at both Passage 0 and in SILAMi.

Figure S3 Heat map of the 187 identified protein groups altered by FOS treatment. Complete protein names are listed in Table S2; a few proteins of interest are indicated. The clustering of rows were generated based on Euclidean distance in Perseus.

Figure S4 Peptide-spectra match quality for the quantified peptide “NNDLPFLMAVEDVMTISGR”. Peptide-spectrum matching was performed using Mascot (v2.3) by searching against a target-decoy version of the HIMPD database. Metrics for both heavy $\left({ }^{15} \mathrm{~N}\right)$ and light $\left({ }^{14} \mathrm{~N}\right)$ peptide identifications are shown. 
Figure S5 Metabolic pathways enriched by FOS-altered microbial proteins. Modules highlighted in red indicate enrichment by FOS-altered proteins. For better visualization, the zoomed-in panel highlights the most enriched pathways.

Figure S6 Influence of monosaccharides on the relative abundance of N-acetyl glucosaminedegrading related proteins. Log2-transformed $\mathrm{L} / \mathrm{H}$ ratios are shown and expressed as mean $\pm \mathrm{SD}$. A two sample t-test was used to compare differences between the non-treated control group $(n=3)$ and the treated sample $(\mathrm{n}=3) .{ }^{*} \mathrm{P}<0.05, * * \mathrm{P}<0.01, * * * \mathrm{P}<0.001$.

\section{Reference}

(1) Jimenez-Rivera, C.; Haas, D.; Boland, M.; Barkey, J. L.; Mack, D. R. Gastroenterol Res Pract 2009, 2009, 518932.

(2) De Boever, P.; Deplancke, B.; Verstraete, W. J Nutr 2000, 130, 2599-2606.

(3) Aries, V.; Crowther, J. S.; Drasar, B. S.; Hill, M. J. Gut 1969, 10, 575-576.

(4) Apajalahti, J. H.; Sarkilahti, L. K.; Maki, B. R.; Heikkinen, J. P.; Nurminen, P. H.; Holben, W. E. Appl Environ Microbiol 1998, 64, 4084-4088.

(5) Liu, F.; Ye, M.; Pan, Y.; Zhang, Y.; Bian, Y.; Sun, Z.; Zhu, J.; Cheng, K.; Zou, H. Anal Chem 2014, 86, 6786-6791.

(6) Chen, R.; Seebun, D.; Ye, M.; Zou, H.; Figeys, D. J Proteomics 2014, 103, 194-203.

(7) Fenyo, D.; Beavis, R. C. Anal Chem 2003, 75, 768-774.

(8) Human Microbiome Jumpstart Reference Strains, C.; Nelson, K. E.; Weinstock, G. M.; Highlander, S. K.; Worley, K. C.; Creasy, H. H.; Wortman, J. R.; Rusch, D. B.; Mitreva, M.; Sodergren, E.; Chinwalla, A. T.; Feldgarden, M.; Gevers, D.; Haas, B. J.; Madupu, R.; Ward, D. V.; Birren, B. W.; Gibbs, R. A.; Methe, B.; Petrosino, J. F.; Strausberg, R. L.; Sutton, G. G.; White, O. R.; Wilson, R. K.; Durkin, S.; Giglio, M. G.; Gujja, S.; Howarth, C.; Kodira, C. D.; Kyrpides, N.; Mehta, T.; Muzny, D. M.; Pearson, M.; Pepin, K.; Pati, A.; Qin, X.; Yandava, C.; Zeng, Q.; Zhang, L.; Berlin, A. M.; Chen, L.; Hepburn, T. A.; Johnson, J.; McCorrison, J.; Miller, J.; Minx, P.; Nusbaum, C.; Russ, C.; Sykes, S. M.; Tomlinson, C. M.; Young, S.; Warren, W. C.; Badger, J.; Crabtree, J.; Markowitz, V. M.; Orvis, J.; Cree, A.; Ferriera, S.; Fulton, L. L.; Fulton, R. S.; Gillis, M.; Hemphill, L. D.; Joshi, V.; Kovar, C.; Torralba, M.; Wetterstrand, K. A.; Abouellleil, A.; Wollam, A. M.; Buhay, C. J.; Ding, Y.; Dugan, S.; FitzGerald, M. G.; Holder, M.; Hostetler, J.; Clifton, S. W.; Allen-Vercoe, E.; Earl, A. M.; Farmer, C. N.; Liolios, K.; Surette, M. G.; Xu, Q.; Pohl, C.; Wilczek-Boney, K.; Zhu, D. Science 2010, 328, 994-999.

(9) Jagtap, P.; Goslinga, J.; Kooren, J. A.; McGowan, T.; Wroblewski, M. S.; Seymour, S. L.; Griffin, T. J. Proteomics 2013, 13, 1352-1357. 
(10) Mesuere, B.; Debyser, G.; Aerts, M.; Devreese, B.; Vandamme, P.; Dawyndt, P. Proteomics 2015, 15, 1437-1442.

(11) Mesuere, B.; Devreese, B.; Debyser, G.; Aerts, M.; Vandamme, P.; Dawyndt, P. J Proteome Res 2012, 11, 5773-5780.

(12) MacCoss, M. J.; Wu, C. C.; Matthews, D. E.; Yates, J. R., 3rd. Anal Chem 2005, 77, 7646-7653.

(13) Park, S. K.; Venable, J. D.; Xu, T.; Yates, J. R., 3rd. Nat Methods 2008, 5, 319-322.

(14) Rauniyar, N.; McClatchy, D. B.; Yates, J. R., 3rd. Methods 2013, 61, 260-268.

(15) Pound, L. D.; Patrick, C.; Eberhard, C. E.; Mottawea, W.; Wang, G. S.; Abujamel, T.; Vandenbeek, R.; Stintzi, A.; Scott, F. W. Diabetes 2015, 64, 4135-4147.

(16) Magoc, T.; Salzberg, S. L. Bioinformatics 2011, 27, 2957-2963.

(17) Aronesty, E., 2011, pp http://code.google.com/p/ea-utils.

(18) Schmieder, R.; Edwards, R. Bioinformatics 2011, 27, 863-864.

(19) Caporaso, J. G.; Kuczynski, J.; Stombaugh, J.; Bittinger, K.; Bushman, F. D.; Costello, E. K.; Fierer, N.; Pena, A. G.; Goodrich, J. K.; Gordon, J. I.; Huttley, G. A.; Kelley, S. T.; Knights, D.; Koenig, J. E.; Ley, R. E.; Lozupone, C. A.; McDonald, D.; Muegge, B. D.; Pirrung, M.; Reeder, J.; Sevinsky, J. R.; Turnbaugh, P. J.; Walters, W. A.; Widmann, J.; Yatsunenko, T.; Zaneveld, J.; Knight, R. Nat Methods 2010, 7, 335-336. (20) DeSantis, T. Z.; Hugenholtz, P.; Larsen, N.; Rojas, M.; Brodie, E. L.; Keller, K.; Huber, T.; Dalevi, D.; Hu, P.; Andersen, G. L. Appl Environ Microbiol 2006, 72, 5069-5072.

(21) Edgar, R. C. Bioinformatics 2010, 26, 2460-2461.

(22) McMurdie, P. J.; Holmes, S. PLoS One 2013, 8, e61217.

(23) Saulnier, D. M.; Gibson, G. R.; Kolida, S. FEMS Microbiol Ecol 2008, 66, 516-527.

(24) Long, W.; Xue, Z.; Zhang, Q.; Feng, Z.; Bridgewater, L.; Wang, L.; Zhao, L.; Pang, X. Sci Rep 2015, 5, 13469.

(25) Yamada, T.; Letunic, I.; Okuda, S.; Kanehisa, M.; Bork, P. Nucleic Acids Res 2011, 39, W412-415.

(26) Tatusov, R. L.; Fedorova, N. D.; Jackson, J. D.; Jacobs, A. R.; Kiryutin, B.; Koonin, E. V.; Krylov, D. M.; Mazumder, R.; Mekhedov, S. L.; Nikolskaya, A. N.; Rao, B. S.; Smirnov, S.; Sverdlov, A. V.; Vasudevan, S.; Wolf, Y. I.; Yin, J. J.; Natale, D. A. BMC bioinformatics 2003, 4, 41. 
Figure S1

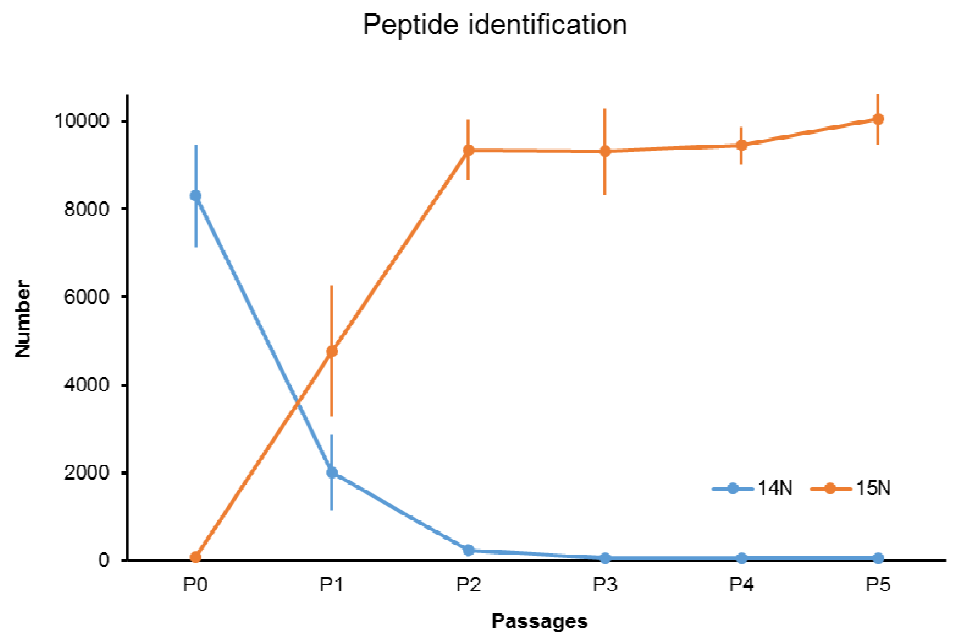

Page S-14 


\section{Figure S2}

A

- Present in both Passage 0 and SILAMi

- Present only in Passage 0

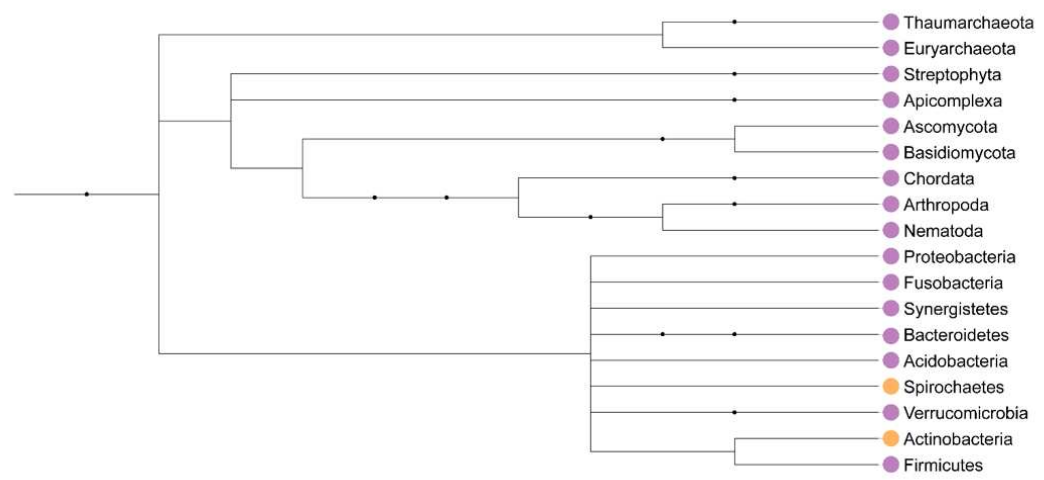

B

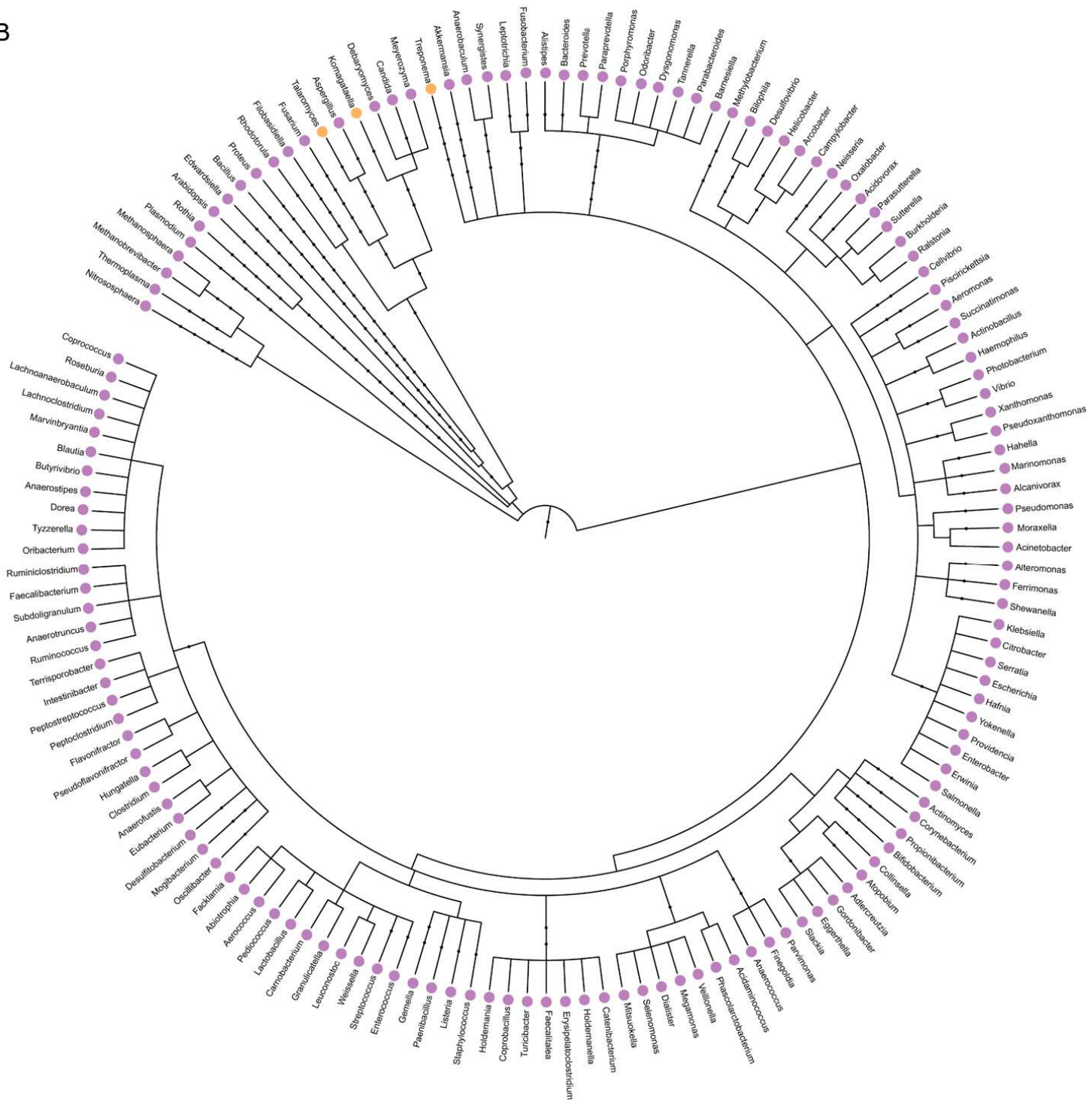

Page S-15 


\section{Figure $\mathrm{S} 2$ continued}
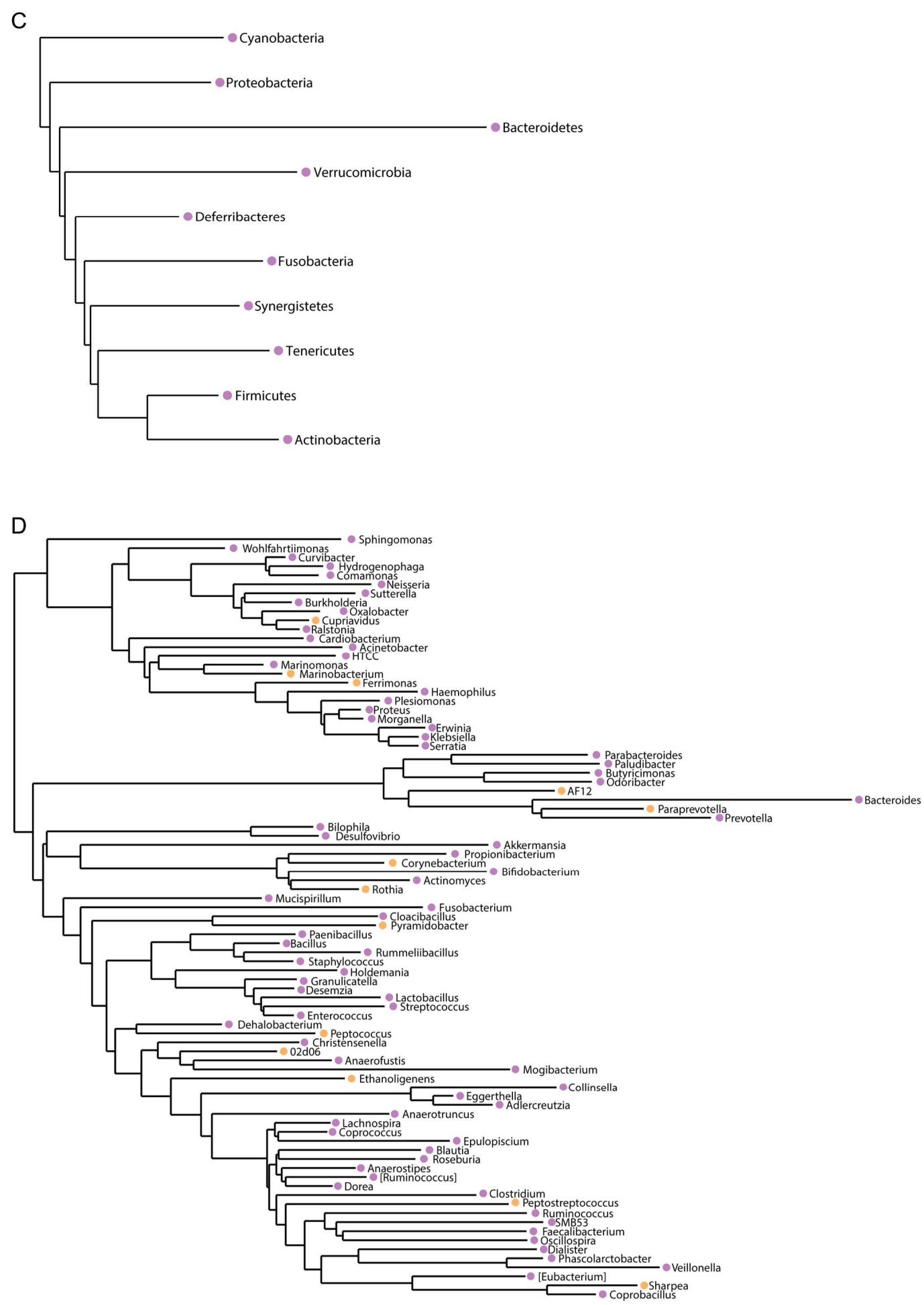

Figure S3

Page S-16 


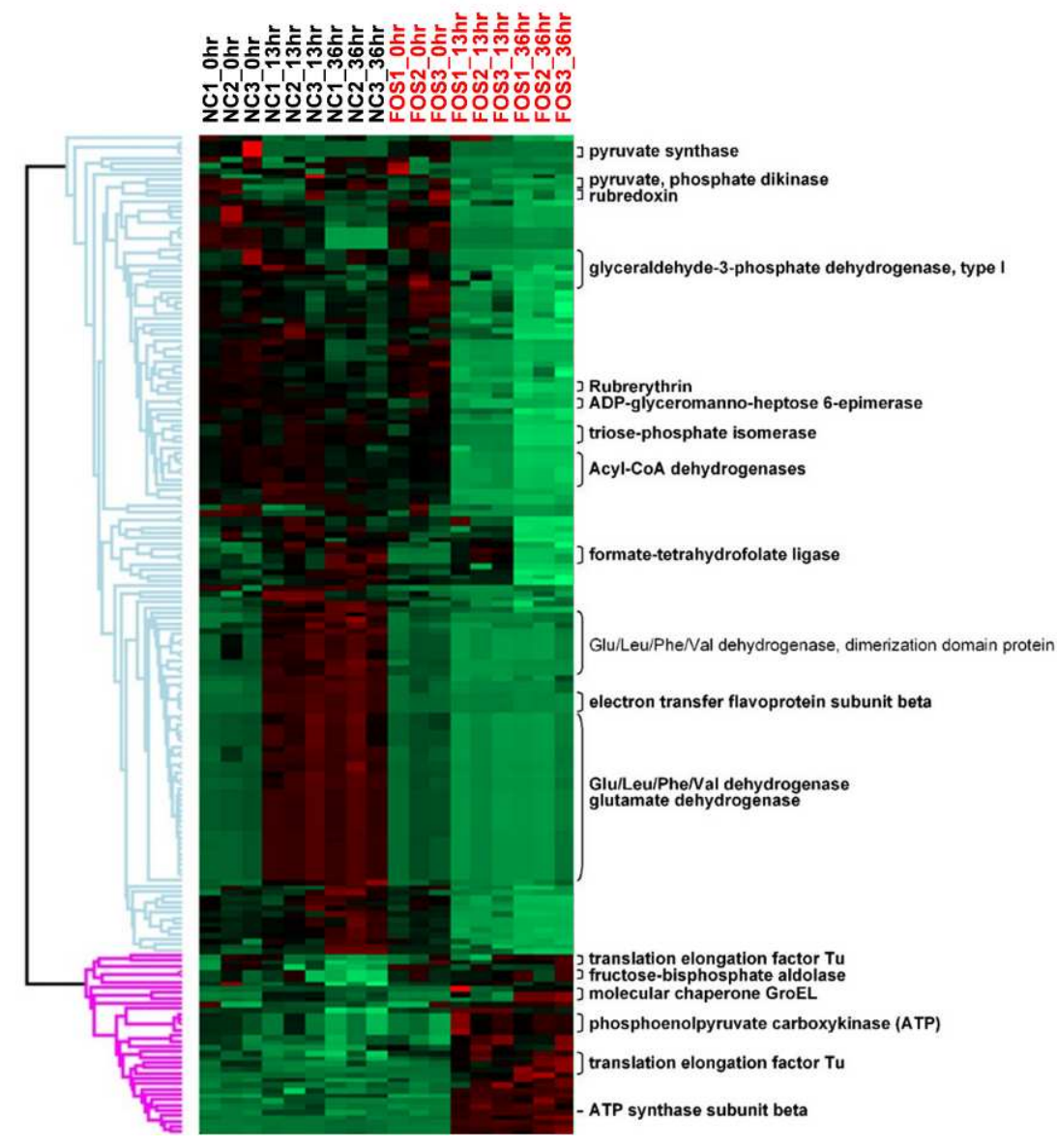

Page S-17 


\section{Figure S4}

MS/MS Fragmentation of NNDLPFLMAVEDVMTISGR

Found in gi|133776067|gb|EBA39887.1|, translation elongation factor Tu [Collinsella aerofaciens ATCC 25986]

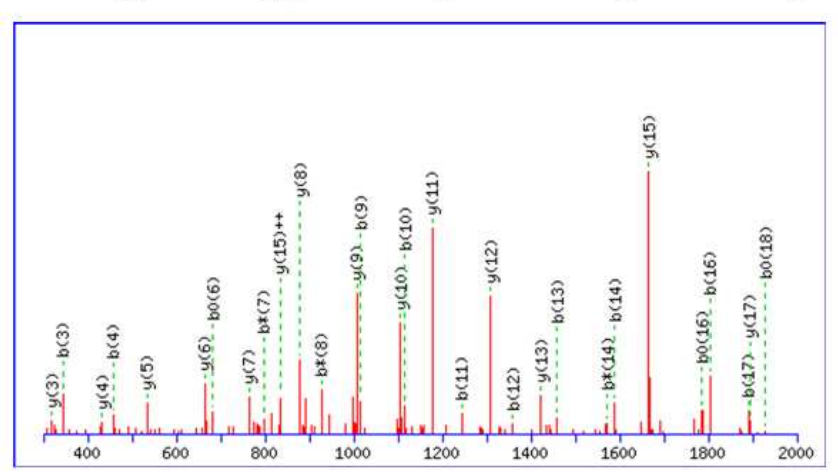

Monoisotopic mass of neutral peptide $\operatorname{Mr}($ calc): 2144.9523

Fixed modifications: Carbamidomethyl (C) (apply to specified residues or termini only)

Component name: heavy
Ions Score: 114 Expect: $1.7 \mathrm{e}-009$

Matches : 29/208 fragment ions using 34 most intense peaks

\begin{tabular}{|c|c|c|c|}
\hline & & $y$ & \\
\hline 117.0443 & $\mathrm{~N}$ & & \\
\hline 233.0813 & N & 2029.9226 & 18 \\
\hline 349.1052 & D & 1913.8856 & 17 \\
\hline 463.1863 & L & 1797.8616 & 16 \\
\hline 561.2361 & P & 1683.7805 & \\
\hline 709.3016 & $F$ & $\mid 1585.7307$ & 14 \\
\hline 823.3827 & L & 1437.6653 & 13 \\
\hline 955.4202 & M & 1323.5842 & \\
\hline 1027.4544 & $A$ & 1191.5466 & \\
\hline 1127.5198 & $\mathrm{v}$ & IIIT.5125 & 10 \\
\hline 1257.5594 & $E$ & 1019.4470 & 9 \\
\hline 1373.5834 & D & 889.4074 & 8 \\
\hline 1473.6489 & $\mathrm{v}$ & 773.3834 & 7 \\
\hline 1605.6864 & $M$ & 673.3180 & 6 \\
\hline 1707.7311 & T & 541.2805 & 5 \\
\hline 1821.8122 & 1 & 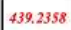 & 4 \\
\hline 1909.8413 & 5 & 325.1547 & 3 \\
\hline 1967.8598 & $\mathrm{G}$ & 237.1256 & 2 \\
\hline & & 179.1071 & 1 \\
\hline
\end{tabular}

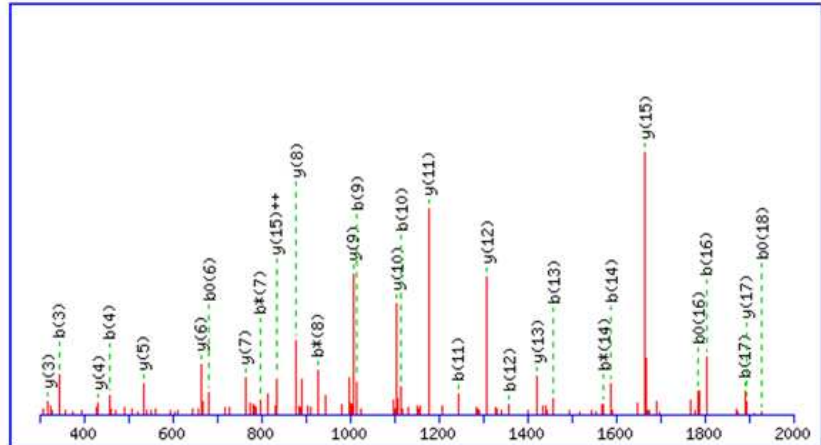

Monoisotopic mass of neutral peptide $\operatorname{Mr}($ calc): 2121.0235

Fixed modifications: Carbamidomethyl (C) (apply to specified residues or termini only)

Compont nam

Matehes : $30 / 208$ fragment ions using 34 most intense peaks

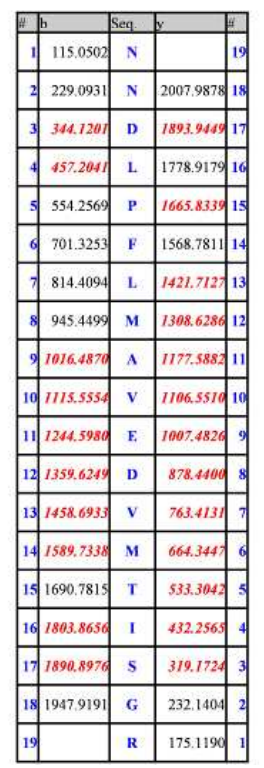

Page S-18 


\section{Figure S5}

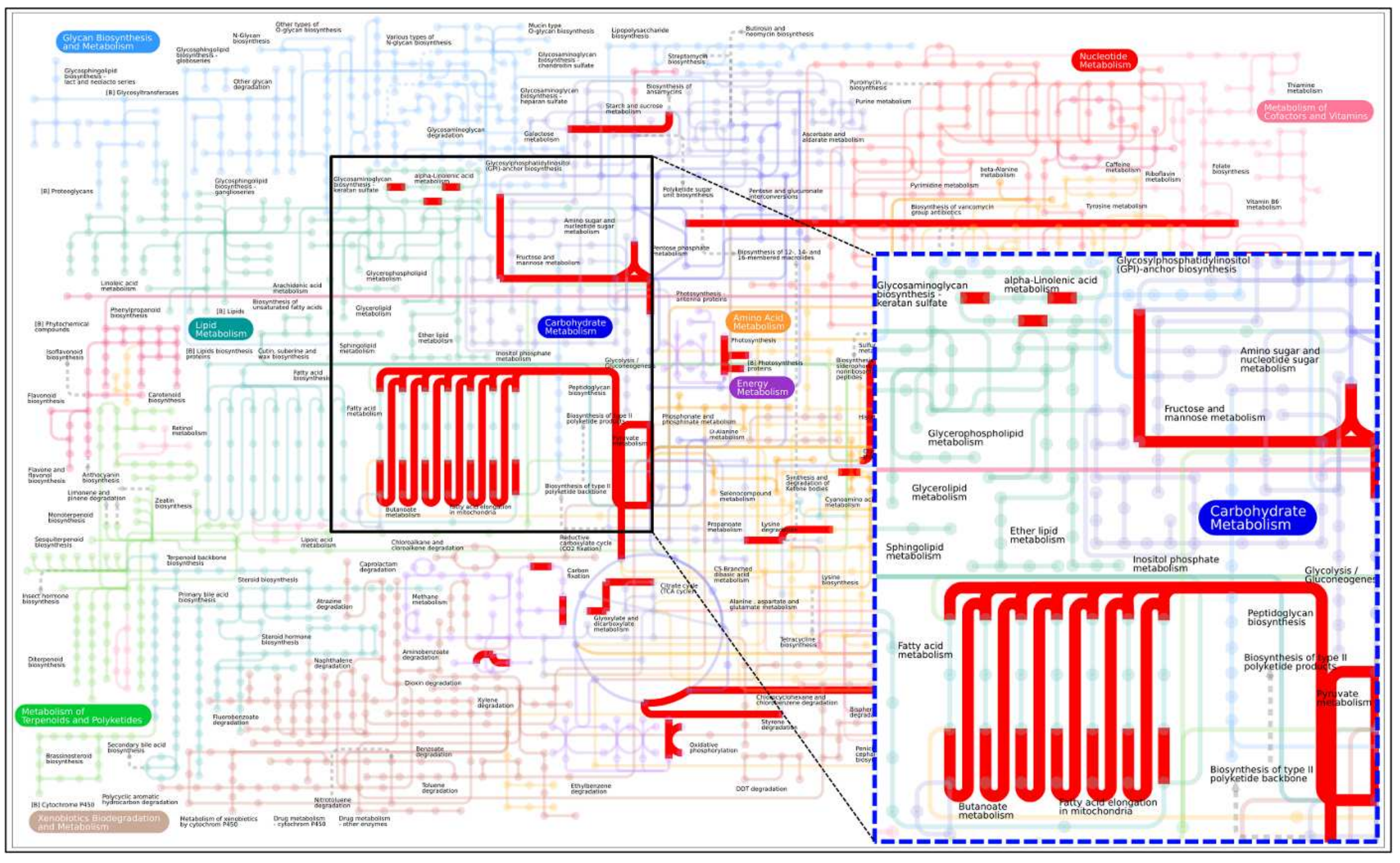


Figure S6
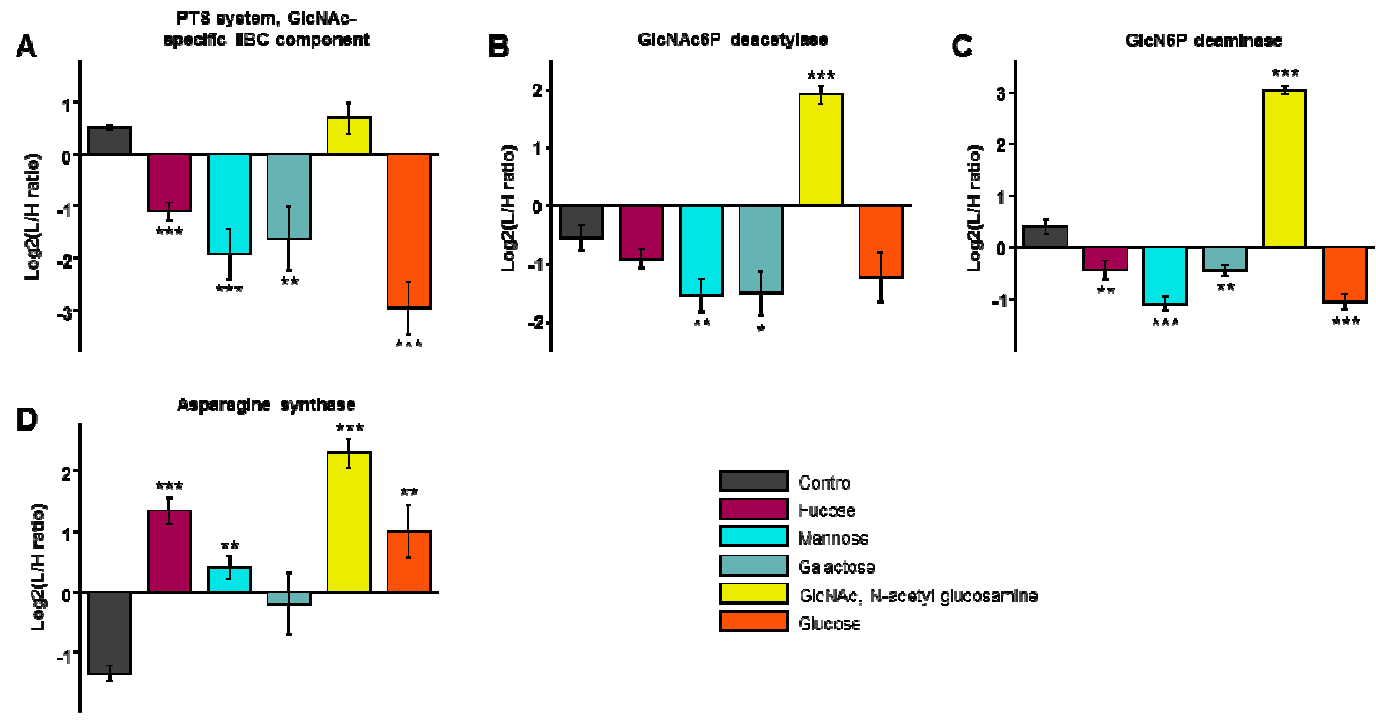

Page S-20 